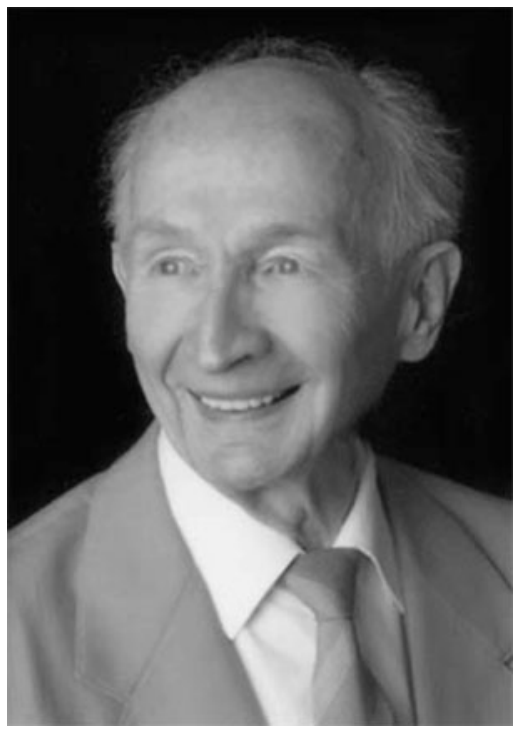

\title{
85th Birthday of Professor Gottfried Glöckner
}

On June 14, 2010, Professor Gottfried Glöckner, formerly chair of Polymer Chemistry at the Technical University of Dresden, is celebrating his 85 th birthday. In consideration of this occasion the scientific community throughout the world congratulates him and wishes him further years in the bosom of his family. His extensive scientific work has been the subject of two laudations published previously in 2000 (Chromatographia 51:653655. DOI: 10.1007/BF02505402) and 2005 (Chromatographia 61:537-538. DOI: 10.1365/s10337-005-0561-4).

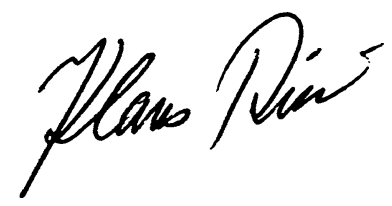

Klaus Rissler 